\title{
The Impact of Covid-19 Crisis on The Hedonic Purchase Behavior: Case of Care Products
}

\author{
Pr Nada SOUDI \\ soudi n@yahoo.fr \\ Management Department, Institut Supérieur de Commerce et d'Administration des Entreprises (ISCAE), Casablanca, \\ Morocco \\ Fadoua BOUALLALA \\ Marketing Graduate Institut Supérieur de Commerce et d'Administration des Entreprises (ISCAE), \\ Casablanca, Morocco
}

\begin{abstract}
The Covid-19 crisis affected the economy as a whole. The rational behavior is becoming more impactful than the spontaneous one and consumers concentrate their purchases on hygienic needs. The purpose of our study is to understand the consequences of such a global pandemic on the hedonic purchase behavior, particularly the care products category. The problematic is: How crisis impacts consumer's behavior towards care products? A cluster analysis was conducted among 255 consumers based on their usage of product care. The study has been conducted during the lockdown and revealed results that will be covered in the following paper.
\end{abstract}

Keywords: Consumer behavior, Covid-19, hedonic purchase, care products.

\section{Introduction}

Since the covid-19 crisis established, our purchasing habits have changed which led to new and different consumption behaviors including those of hedonic purchase. The Covid-19 crisis is now reshaping consumer's behavior. The beauty industry has been significantly affected. Beauty trends and routines are changing very quickly. However, whether it is a significant or less significant drop, companies are imperatively looking to evaluate and analyze its impact on consumer habits in order to cope with this exceptional phase. The main objective of this study is to understand, analyze and break down new hedonic purchase habits during the exceptional Covid-19 circumstances. The study was conducted during the lockdown and revealed that "homemade" is the new trend. This study intends to find the new changes, habits and facial care gestures during the lockdown. A questionnaire covered a sample of 255 women, consumers of facial care products.

1 Joanis, H. (1964). Choix dans l'axe psychologique. Communication \& Langages, Vol. 12, pp. 68-78.

${ }^{2}$ Sethna, Z. and Blythe, J. (2008). Consumer Behaviour, p. 194, 2008.

The current issue and full text archive of this journal is available at www.jraspublications.org/index.php/JRAS/issue/archive

Journal of Research in Administrative Sciences (JRAS)

V IX(II), 40-44, ISSN: 2664-2433

\section{State of art}

Consumption is everywhere in our daily lives. Individuals no longer consume to express what they are but also what they would like to be. Companies have understood that the consumer is a complex being whose decisions vary from one environment to another and above all change over time. Satisfying them or building their loyalty requires knowledge of all the variables and factors that influence their purchasing decisions.

Henri Joannis ${ }^{1}$ (1964) identified 3 types of motivations including hedonistic motivations which are made mainly to please each individual personally. Hedonism can be defined as «the cult of pleasure. In consumer behavior, it refers to the pleasurable aspects of consumption» (Blythe, $2004)^{2}$. Belaid and $\mathrm{Al}^{3}$ (2017) studied the feedback and assessment of consumers towards hedonic, symbolic or functional attributes of brands.

\footnotetext{
${ }^{3}$ Belaid, S., Ben Mrad, S., Lacœuilhe, J. Tlili and Tlili-Turki, H. (2017,
} 
The Impact of Covid-19 Crisis on The Hedonic Purchase Behavior: Case of Care Products

PrNada SOUDI, Fadoua BOUALLALA
Journal of Research in Administrative Sciences

Volume IX, Issue II, 2020, 40-44
C. Hirschman and B. Holbrook are originally behind the hedonic consumption and consider the concept as «those facets of consumer behavior that relate to the multisensory, fantasy and emotive aspects of one's experience with product». (1982) ${ }^{4}$. Four hedonic perspectives can be defined: mental constructs, product classes, product usage, and individual differences.

P. Hébel - N. Siounandan $(2009)^{5}$ believe that 2008 economic crisis had a great impact on French consumer's behavior. While some categories consumption experienced a slowdown, others on the other hand experienced strong demand. Ethical or sustainable consumption emerged, as consumers questioned hyper-consumption and enhanced ethical and collective interests when making purchasing decisions.

Four types of consumption have emerged:

- Committed consumption: the priority of consumers no longer has individual interests but rather collective interests. Consumers seek to go beyond their own needs and desires to achieve a greater purpose which is consumption based on ethical and social principles.

- Functional consumption: the crisis has significantly affected the market, leading to a drop-in price. Consumers no longer seek to assert themselves by the number of goods they own. It is now consumption experiences that allow personal fulfillment that determine purchasing decisions.

- Co-production: the consumer seeks to contribute to the production process and add his own signature to it.

- Dematerialized consumption: with the advent of e-commerce, a new era of digitalization has begun thanks to websites and digital platforms. Internet introduced consumers to a new form of consumption: the "smart buying".

The 2008-2009 crisis has not certainly changed the main aspects of consumption. However, other trends emerged, engaged consumption continued to grow, the Internet in turn became a great success, which continued to develop after the crisis.

P. Hébel, T. Mathé (2015) ${ }^{6}$ define consumer's profiles within a post-crisis period, particularly 2015 post-crisis. In order to understand better the purchasing behavior of consumers during these exceptional circumstances, a study was conducted in order to classify consumer's typologies during a crisis. It consisted of a sample of 1.000 individuals aged 18 and over.

Seven typologies of consumers have been identified:

- The basics, representing $19 \%$ of the population, are those whose consumption does not change. They buy the bare necessities, are only interested in basic needs and do not seek additional expenses.

- The well-off, representing $17 \%$ of the population, are financially stable and have no difficulties in making purchases. They favor quality and are very sensitive to ecological and organic products

- The thrifty, representing $22 \%$ of the population, are looking for bargains and low prices. Savings are very important; they tend to buy during promotions and sales.

- Strategists, who represent $21 \%$ of the population, adopt strategies during the crisis period to save money. Strategists are always looking for perfect plans.

- The constraints, representing $14 \%$ of the population, are facing financial difficulties, and have to limit their consumption to survive the crisis.

- Committed consumers, representing $14 \%$ of the population, are interested in the frugal aspects of each product and are more likely to reuse it for different purposes.

November). Are consumers leaning towards hedonic, symbolic or functional attributes? Brand benefits scale development and validation in emerging markets. Revue Française du Marketing, Paris $N^{\circ}$ 261: 65-79.

${ }^{4}$ Elizabeth C. Hirschman and Morris B. Holbrook, (Summer, 1982). Hedonic Consumption: Emerging Concepts, Methods and Propositions. Journal of Marketing, Vol. 46, No. 3 pp. 92-101.
- Innovation researchers representing $12 \%$ of the population, are the people who choose innovation and technical progress as the main criteria before buying a product.

These seven typologies show that consumers can adopt different strategies to meet their needs. However, the aim is the same, which is to consume and overcome these difficult circumstances, each according to their resources.

In fact, in 2015, consumption extended to the digital domain. Internet changed the game and introduced consumers to a new digital era.

K. Belmouss $(2011)^{7}$ assume that consumers are more attentive to their purchasing behavior during periods of crisis. They tend to reduce their spending and benefit from the best offers. To limit crisis damages, it is important for companies to adapt, understand new behaviors and respond to new consumer's demands.

More than ever before, companies need to focus on new courses of action. They must undoubtedly retain customers and readjust all components of the marketing-mix. Companies must develop a crisis culture and prepare a crisis management plan to overcome any potential threats.

It is also important to exploit and preserve brands, companies must capitalize on brands to meet consumer's expectations, using new languages and marketing techniques. Finally, invest in innovation. Innovation allows companies to be distinguished from competition.

Crises undoubtedly influence consumer's behavior. That is why it is important for companies to learn from what the previous experiences may have brought over time. In order to overcome these difficult times and ensure their sustainability, companies must adopt the appropriate strategies and deal with changes in consumer behavior and purchasing power. This includes adjusting the marketing mix, implementing innovation in terms of offer and brand management through communication. Hence, we can study deeply our problematic:

\section{How crisis impacts consumer's behavior towards care products?}

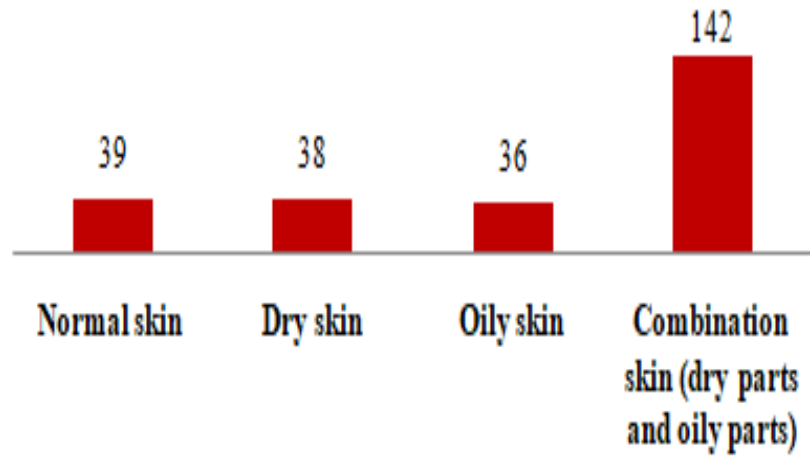

Fig. 1. Skin types of the sample

\section{Sample characteristics}

A quantitative study was conducted in order to understand facial care products user's behavior during this time of Covid-19 crisis. The sample selected for this study consisted of 255 respondents. All of them are Moroccan women aged between 18 and 45 .

${ }^{5}$ Hébel, P., Siounandan, N. and Lehuédé, F. (2009, December). Will consumer behaviour change durably with the crisis?

${ }^{6}$ Hébel, P. and Mathé, T. (2017, November). Representation of consumption at the end of the economic crisis.

${ }^{7}$ Belmouss, K. (2011). What marketing strategy to face the international financial crisis? $\mathrm{N}^{\circ} 4-5$. 
The Impact of Covid-19 Crisis on The Hedonic Purchase Behavior: Case of Care Products

Pr Nada SOUDI, Fadoua BOUALLALA

\begin{tabular}{c|c}
\hline Age & $(\%)$ \\
\hline $18-25$ & 58.27 \\
\hline $26-35$ & 37.80 \\
\hline $36-45$ & 3.93 \\
\hline
\end{tabular}

Table 1: Sample characteristics

More than half of the respondents $(55.7 \%)$ describe their skin as a combination skin (dry and oily parts). The remaining skin types - normal skin, dry skin and oily skin - share about the same percentage, around 14$15 \%$.

This sample will allow us to study deeply their behavior changes during the lockdown and how they change their routine in these new circumstances.

\section{Results and Discussion}

The period of lockdown has indeed changed certain behaviors, new routines and trends have emerged. Meanwhile others stagnate or are less used by our consumers.

First, five consumer profiles can be identified

- The trustworthy: These consumers are attached and are faithful to one single brand. They do not seek to use other brands and are very satisfied with the results obtained.

- The capricious: These consumers alternate between two or more different brands. They have no particular attachment to a particular brand.

- The luxurious: These are consumers with a high care budget. They adopt relatively expensive brands to take care of their faces.

- The fearful: Consumers who only buy approved dermatological brands.

- The curious: These consumers tend to try disruptive products, new products with high growth potential. We are talking about brands like Pixi, The Ordinary or St. Yves.

The respondents use one or more of these brands to take care of their faces which explain the profiling already established above.

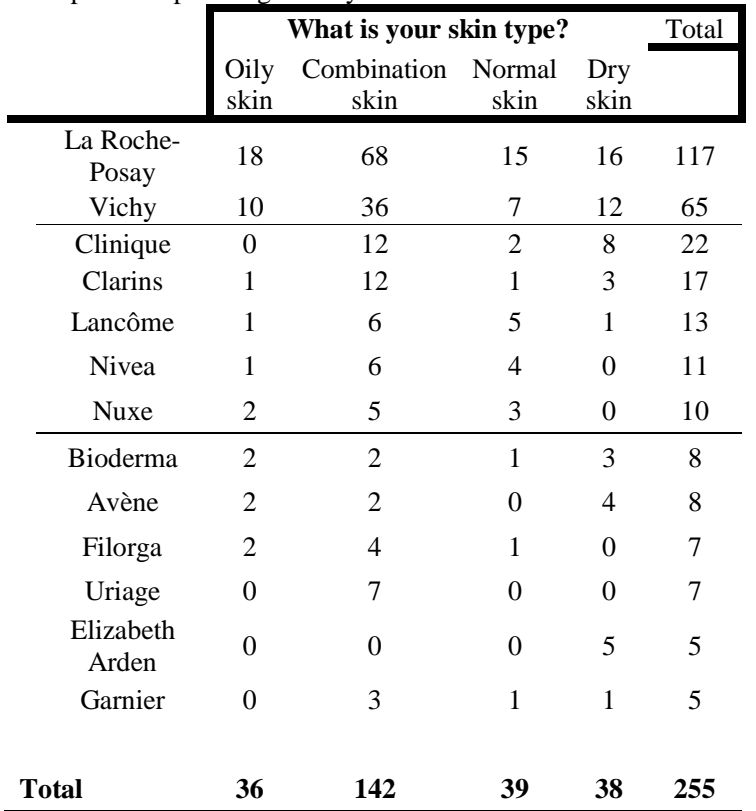

Table 2: Most used brands during the lockdown period for each skin type. Moreover, natural facemasks are growing strongly in these weeks of lockdown, $49 \%$ make natural homemade masks. Natural ingredients are perceived as less aggressive especially for the facial skin. It should also be noted that of the $20 \%$ of the sample who switched brands, $45 \%$ of them said they had enough free time to prepare their own homemade masks while $22 \%$ preferred to try natural products.

In terms of respondent's purchasing behaviors, before the lockdown the most frequent places of purchase are pharmacies and drugstores. During the lockdown, we observed a significant increase in e-commerce: $55 \%$ of respondents purchased facial care products on online platforms (vs. 11\% before the lockdown). However, pharmacies and drugstores remain the main places of purchase during the lockdown for $58 \%$ (vs. $80 \%$ before the lockdown).

\begin{tabular}{ll} 
Main purchase place before the lockdown & $(\boldsymbol{\%})$ \\
\hline Pharmacies/parapharmacies & $80 \%$ \\
Online web sites & $7 \%$ \\
Supermarkets & $6 \%$
\end{tabular}

\begin{tabular}{lc}
\multicolumn{2}{l}{ Main purchase places durring the lockdown } \\
\hline & $(\%)$ \\
\hline *Pharmacies/parapharmacies & $58 \%$ \\
Online parapharmacies* & $14 \%$ \\
Supermarkets & $9 \%$ \\
Online web sites & $4 \%$ \\
IHerb & $3 \%$ \\
Beautybay & $3 \%$
\end{tabular}

*Online Pharmacies (e.g MaPara

Citymall, Contepara)

Table 3: Main purchase places before and during the lockdown.

Added to that, consumers have adopted new gestures, $64 \%$ of women no longer wear make-up during this period, hence the significant decline in the use of some products such as make-up remover and micellar cleansing water. This reluctance towards make-up is quite logical and can be explained by two main reasons: some of the women are no longer motivated enough to wear make-up because they have nowhere else to go, meanwhile others simply prefer to let their skin rest now that they have the opportunity to do so.

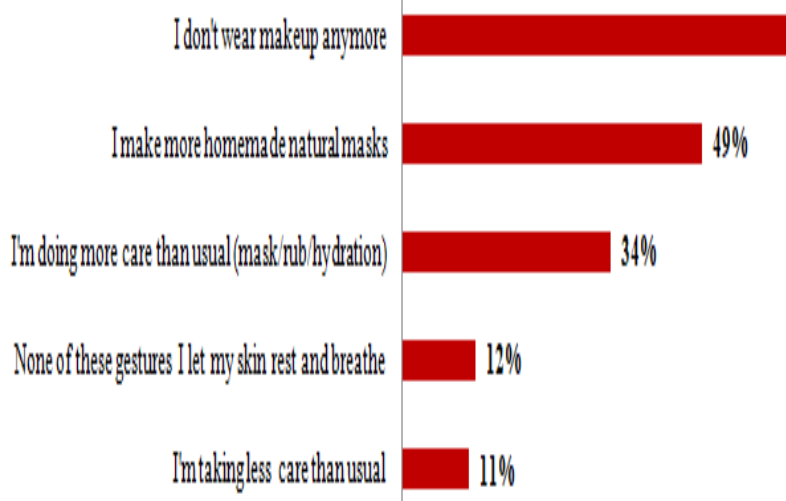

Fig. 2: New behaviors since the lockdown.

Finally, many women have noticed changes in their skin over the weeks. Two types of changes can be distinguished: positive changes and negative changes.

One the one hand, four main positive changes were observed, $32 \%$ of the sample have noticed a more hydrated skin, $28 \%$ a softer skin especially for consumers with mixed and dry skin.23\% less pimples and for $19 \%$ more luminous skin mostly women with mixed skin. 
On the other hand, there are two major negative changes namely the appearance of pimples $(31 \%)$ especially for women with mixed skin and spots $(9 \%)$, this change particularly concerns women with mixed and oily skin.

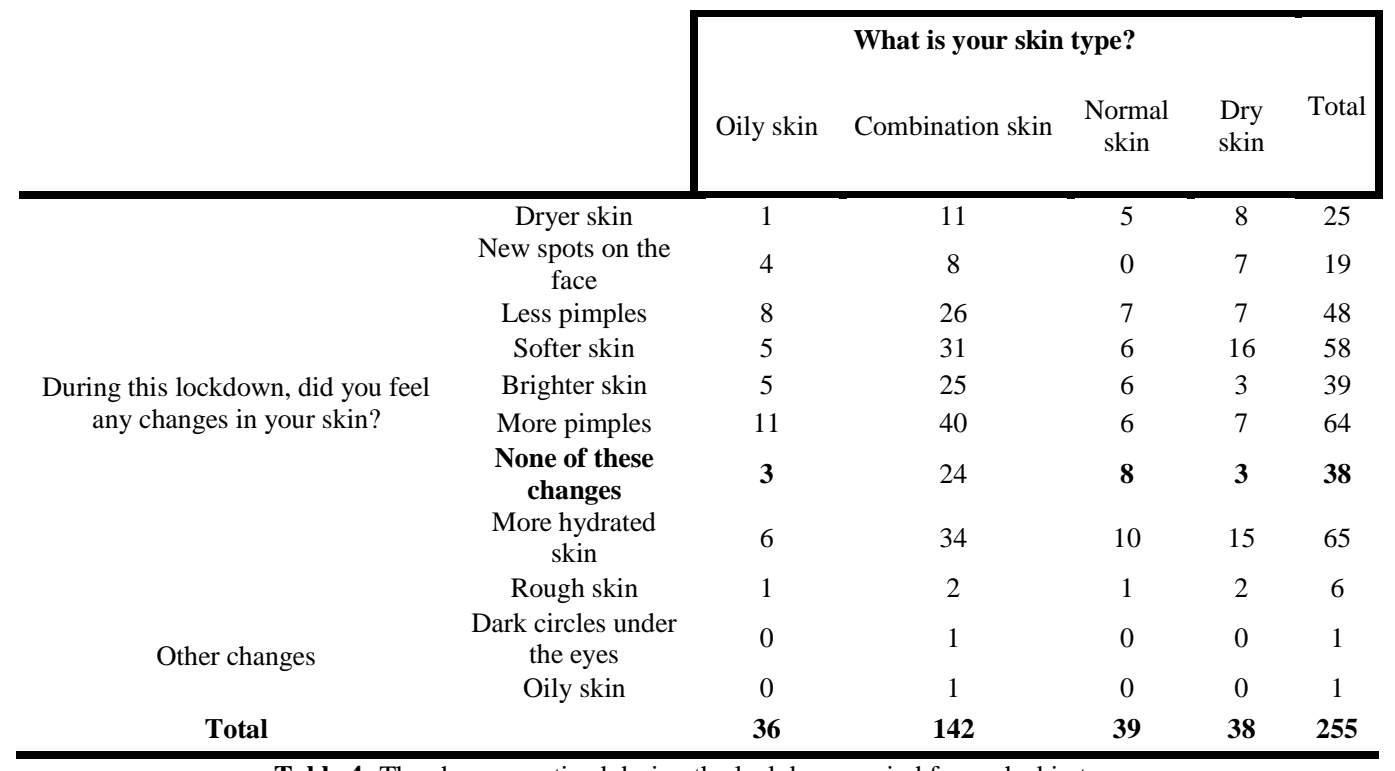

Table 4: The changes noticed during the lockdown period for each skin type

This study allows us to highlight that during the lockdown women were more concentrated on taking care about their selves with natural and simple product, rather than applying cosmetics for being beautiful. The concentration was about heath and not beauty. That is why there was a success in homemade masks, but less in makeup.

\section{Conclusion}

It is important for every company's managerial interest to understand the impact of the Covid-19 crisis on the consumption habits. The new consumer trends will allow the company to adapt their products and services and to develop pull innovation that emerged from their new usages and the changes in their consumption. This is related to the social and hedonistic innovations (G. Roehrich ${ }^{8}$, 1994) that describe innovativeness, or the tendency to buy new products, to express two types of needs: the need for stimulation and the need for uniqueness.

Also, J. Michaud ${ }^{9}$ (2006) measured the hedonistic and utilitarian components of the attitude towards different categories of cosmetic products according to brands belonging to different degrees of luxury.

According to this study, two major concepts emerged:

The new trend of homemade masks: this new way to consume is about the concentration on natural products when there is time availability because women had enough time to take care of their skin.

The lockdown was an occasion for many women to search special natural recipe to enhance the quality of their skin even it takes time on preparation and applying. The operational perspective of the company is to develop natural products with simple ingredients, that can be practical to use and to apply and claim their natural add value.

A lack of interest during these circumstances to go towards make-up: this new trend is about stop using chemical products and let their skin rest. It seems that women apply cosmetics rather for being beautify outside

\footnotetext{
${ }^{8}$ Roehrich, G. (1994, June). Innovativités hédoniste et sociale : proposition d'une échelle de mesure.

${ }^{9}$ Michaud, J. (2006). Measurement of the hedonistic and utilitarian components of the attitude towards different categories of cosmetic
}

than as a beauty routine. It's not about accomplishment need but esteem one.

The operational perspective of the company is to develop natural makeup products that allow women to maintain their beauty routines as well as to reform their skin. In fact, companies must highlight two main aspects health first and beauty as a consequence of a healthy skin.

It is indeed crucial and more than ever necessary for brands to be attentive to their consumers in order to overcome the consequences of the post-crisis period and to innovate according to new consumers trends especially of hedonic purchases.

\section{References}

i. Belaid, S., Ben Mrad, S., Lacœuilhe, J. Tlili and Tlili-Turki, H. (2017). Are consumers leaning towards hedonic, symbolic or functional attributes? Brand benefits scale development and validation in emerging markets. Revue Française du Marketing, Paris $\mathrm{N}^{\circ}$ 261: 65-79.

ii. Belmouss, K. (2011). What marketing strategy to face the international financial crisis? $\mathrm{N}^{\circ} 4-5$

iii. Elizabeth C. Hirschman and Morris B. Holbrook, (1982). Hedonic Consumption: Emerging Concepts, Methods and Propositions. Journal of Marketing, Vol. 46, No. 3 pp. 92-101.

iv. Hébel, P. and Mathé, T. (2017, November). Representation of consumption at the end of the economic crisis.

v. Hébel, P., Siounandan, N. and Lehuédé, F. (2009). Will consumer behaviour change durably with the crisis?

vi. Joanis, H. (1964). Choix dans l'axe psychologique. Communication \& Langages, Vol. 12, pp. 68-78.

vii. Michaud, J. (2006). Measurement of the hedonistic and utilitarian components of the attitude towards different categories of cosmetic

product according to brands belonging to different degrees of luxury. Rr Rapport de Maîtrise. 
The Impact of Covid-19 Crisis on The Hedonic Purchase Behavior: Case of Care Products

PrNada SOUDI, Fadoua BOUALLALA
Journal of Research in Administrative Sciences

product according to brands belonging to different degrees of luxury. Rapport de Maîtrise.

viii. Roehrich, G. (1994, June). Innovativités hédoniste et sociale: proposition d'une échelle de mesure.

ix. Sethna, Z. and Blythe, J. (2008). Consumer Behaviour, p. 194. 